\title{
Analysts' Earnings Forecasts: Coexistence and Dynamics of Overconfidence and Strategic Incentives
}

\author{
Accepted for publication in Accounting and Business Research 2015
}

\begin{abstract}
This paper formulates a two-stage model to capture the decision process of financial analysts when issuing earnings forecasts. Our model extends the model of Chen and Jiang (2006) by allowing for a distortion of forecasts independent of whether an analyst has private information. Using quarterly earnings forecasts, we provide empirical evidence on the coexistence of overconfidence and strategic incentives. Financial analysts overweight their private information and at the same time strategically inflate their forecasts.
\end{abstract}

Keywords: Financial analysts, Earnings Forecasts, Overconfidence, Conflicts of interest.

JEL-classifications: G14; G17; G24 


\section{Introduction}

Financial analysts are an important source of information to the stock market in the valuation of firms (Schipper 1991). They assimilate and process publicly available information, acquire private information and disseminate new information by issuing earnings forecasts and recommendations. It is, however, well documented that financial analysts' earnings forecasts systematically deviate from rationality (De Bondt and Thaler 1990, Abarbanell 1991, Brown 1997, and Easterwood and Nutt 1999). Different explanations are put forward to explain these forecast inefficiencies. Broadly speaking, the systematic deviations from rationality in the decision making process can be assigned to either a behavioral bias or a strategic bias (Friesen and Weller 2006).

Even though the literature analyzing financial analysts is quite elaborate, Ramnath et al. (2008) conclude that much of the decision process remains hidden in a black box. Studies often focus on either the behavioral bias (see e.g. Barber and Odean 2001 and Hilary and Menzly 2006) or the strategic bias (see e.g. Dugar and Nathan 1995 and Ljungqvist et al. 2007). When both biases are jointly taken into account, as in Chen and Jiang (2006), they are formulated as mutually exclusive hypotheses. In this paper, we therefore build upon this last model and extend it to incorporate distortions at two different stages, instead of a single distortion. Such model allows to jointly determine a behavioral bias and a strategic bias and is therefore more flexible. In the first stage, analysts perform a fundamental analysis in which they combine public and private information to form their initial forecast. During this first stage, analysts can introduce a bias by over- or underweighting the information they have. In a second stage, a financial analyst can introduce an additional distortion by inflating or deflating his initial Bayesian forecast.

By introducing a two-stage model to explain analysts' decision process, we contribute to the literature in multiple ways. First, our model is more flexible. We not only introduce two different mechanisms by which analysts can distort their forecasts, we also allow the analyst to distort his forecast, even in the case where he has no private information that he can over- or underweight. Second, by introducing two separate distortions, our model has the potential to separately capture the presence of a behavioral bias as well as a strategic bias. Therefore, a key feature of our model is that both biases, behavioral and strategic, can coexist and that we are able to identify the behavioral 
and strategic bias separately. This is in contrast to existing analytical models where these biases are typically modelled as mutually exclusive.

To test whether our model with two separate mechanisms of bias is empirically relevant, we estimate it on a large sample of quarterly earnings forecasts. In addition, we consider different settings that allow us to further analyze the two distortions in an attempt to define them as a behavioral or a strategic bias. We document the existence of two separate mechanisms of distortion. Our empirical results indicate that financial analysts overweight the precision of their private information and additionally inflate their forecast. Furthermore, we find that the first-stage bias resembles a behavioral bias, while the second-stage distortion appears to be strategic in nature. In particular, when estimating our model separately on a sample of male versus female analysts, we find that the first-stage distortion is significantly higher for male analysts than for female analysts. The second-stage distortion is similar for both. While differences among men and women should disappear among sophisticated individuals (see e.g. Croson and Gneezy 2009), Adams and Funk (2010) show that differences can still exist for a number of reasons, including gender discrimination in the access to the position. Interesting evidence is also given by Can Inci et al. (2014) who show that gender differences exist among senior executives due to differences in access to inside information. To further substantiate this finding, we show that the second stage bias does conform to a strategic bias. In particular, new analyst regulation enforced in 2002 to increase the objectivity of financial analysts, and thus targeted at the strategic bias, only impacts the second-stage distortion, and not the first-stage distortion. This suggests that this second-stage bias is driven by strategic considerations. Finally, a similar conclusion follows from the analysis of first forecasts versus last revisions. In line with existing literature on the walk down from optimistic to more pessimistic forecasts within the same quarter (see e.g. Richardson et al. 2004), we also observe a walk down in the second-stage distortion. Again this leads us to conclude that this second distortion is strategic in nature.

The remainder of this paper is organized as follows. Section 2 discusses the two-stage decision model. Section 3 explains the empirical methodology and Section 4 presents the empirical results. Section 5 contains a robustness check and finally, Section 6 concludes. 


\section{The Two-Stage Model}

In this section we introduce a two-stage model that represents the decision process of financial analysts. We build upon the model of Chen and Jiang (2006), but extend it to allow for a more generic decision process. The first stage of our model is identical to the Chen and Jiang (2006) model. Financial analysts perform an analysis in which they combine public and private information into an earnings forecast. The assimilation of public and private signals is modelled as a Bayesian expectation formation, which is a common approach in the earnings forecast literature (e.g. Chen and Jiang 2006 and Martinez 2011). Following Gervais and Odean (2001) and Chen and Jiang (2006), $a$ is defined as the announced earnings of a firm. These announced earnings follow a diffuse zero-mean normal distribution; $c$ is defined as a statistic for all public information about $a$ :

$$
c=a+\varepsilon_{c} \quad \text { with } \varepsilon_{c} \sim N\left(0, \frac{1}{p_{c}}\right)
$$

In this set-up $p_{c}$ is the precision of the public signal. We further assume that $x$ is the analyst's private information about announced earnings $a$ :

$$
x=a+\varepsilon_{x} \quad \text { with } \varepsilon_{c} \sim N\left(0, \frac{1}{p_{x}}\right)
$$

where $p_{x}$ is the precision of the analyst's private signal and where $\varepsilon_{x}$ is independent from $\varepsilon_{c}$. Using Bayes' rule we define the analyst's best forecast of actual earnings conditional on his private information $(x)$ and his public information $(c)$ as:

$$
E(a \mid x, c)=h x+(1-h) c
$$

where $h \cong \frac{p_{x}}{p_{x}+p_{c}} \in[0,1]$ is the precision of the analyst's private signal relative to the public information. Of course, when an analyst interprets and weights publicly available information and private information, he may be influenced by a bias. This could lead him to deviate from the rational weighting scheme as summarized in $h$, and instead induce him to use his personal scheme $k$ to obtain his Bayesian earnings forecast $f_{b}$ : 


$$
f_{b}=k x+(1-k) c
$$

where $k \in[0,1]$ is the weight the analyst puts on his private signal. The more $k$ differs from $h$, the more the analyst deviates from the optimal, rational forecast. An analyst who overweights private information is characterized by $k / h>1$, while an analyst who underweights private information has $k / h<1$.

While theoretically sound and attractive, the above specification only allows for a biased forecast in case there is a private signal $x$ that is different from the public signal $c$. However, it could very well be that an analyst does not possess any private info and still issues a forecast that is different from the optimal consensus. Therefore, we want to allow for a more generic and flexible decision model, where distortion of the forecast is possible even if the analyst does not have a distinctive private signal. We therefore introduce a second stage, where an analyst can distort his initial Bayesian forecast $f_{b}$. This second-stage bias is modelled as a multiplicative distortion $s$ of the initial Bayesian forecast $f_{b}$ :

$$
f=s f_{b}
$$

where $f$ is the final earnings forecast as issued to the public and $s$ the degree of second-stage distortion. An analyst who only strives for the most accurate forecast should have $s=1$. A distortion factor $s \neq 1$ then corresponds to a strategic inflation/deflation of the Bayesian forecast, depending on the sign of this initial forecast. A distortion factor s $>0$ implies that analysts do not change the sign of their initial forecast, while $s<0$ implies that the sign of the initial Bayesian forecast is strategically reversed. For the empirical analysis in the current paper, where we restrict ourselves to positive final forecasts, we expect a distortion factor that is positive. ${ }^{1}$ Intuitively, a distortion $s>1$ then corresponds to strategic inflation, while a distortion factor $0<\mathrm{s}<1$ points to deflation. A positive distortion factor is motivated by the evidence that forecast accuracy matters (see e.g. Gu and Wu 2003 and Hilary and Zhu 2013), making it less likely that analysts reverse their

\footnotetext{
${ }^{1}$ We also estimate the model on the full sample of positive and negative forecasts, and results remain unchanged.
} 
initial Bayesian forecasts. This is reasonable for initial positive and initial large negative forecasts ${ }^{2}$, but it is possibly not valid for initial negative, but near-zero forecasts. For the latter, a reversal could be strategically interesting. However, the frequency of occurrence of such forecasts in our sample is most likely to be very low.

The identification of two separate distortions in our model is appealing. Indeed, as previous literature has shown analysts are prone to overconfidence as well as strategic incentives. Our model has the potential to capture both and to identify them separately if their dynamics are indeed different. The first stage weighting scheme can either capture strategic incentives, behavioral bias, or both. The same holds for the second multiplicative distortion factor. Which distortions are present, and what its dynamics are, is ultimately an empirical question that we try to solve in this paper.

\section{Estimation methodology}

To obtain estimates of the two distortions, we need to rely on reduced form estimation. Using the above model set-up as defined in equations (1) - (5), the expected forecast error can be defined as:

$$
E(F E \mid x, c)=E(f-a \mid x, c)=s(k x+(1-k) c)-(h x+(1-h) c)
$$

where $F E=f-a$ is the forecast error. Rearranging and applying a first-order Taylor approximation to the biases around $k / h=1$ and $s=1$ allows for a separate identification of both biases: ${ }^{3}$

$$
E(F E \mid x, c)=\left(\frac{k}{h}-1\right)(f-c)+(s-1) f=\beta_{1}(f-c)+\beta_{2} f
$$

where $\beta_{1}$ and $\beta_{2}$ reflect the first-stage and second-stage bias, respectively. If, in contrast to our hypothesis, only the first-stage bias distorts analysts' earnings forecasts, the model reduces to the moment condition $E[F E]=\beta(f-c)$ as derived by Chen and Jiang (2006). If this is indeed the

\footnotetext{
${ }^{2}$ As analysts are reluctant to issue negative forecasts, stocks with such very negative future prospects are possibly dropped from coverage (see McNichols and O’Brien 1997).

${ }^{3}$ A full derivation can be found in Appendix A.
} 
case, any additional term to this moment condition should not be empirically relevant, which implies $\beta_{2}=0$.

To test our model, the reduced form equation (7) is estimated using the following regression model:

$$
F E_{i k t}=\alpha+\beta_{1} D e v_{i k t}+\beta_{2} f_{i k t}+\delta_{i} X_{i k t}+\varepsilon_{i k t}
$$

with $i$ an analyst identifier (who issues the forecast), $k$ a company identifier (on which a forecast is issued) and $t$ a time identifier (to which quarter the forecast pertains). $F E_{i k t}=f_{i k t}-a_{k t}$ is the forecast error made by analyst $i$ in quarter $t$ for company $k$, calculated as the difference between the forecasted $f_{i k t}$ and actual $a_{k t}$ earnings per share. $D e v_{i k t}=f_{i k t}-c_{k \tau}$ is the deviation from the consensus and is determined as the difference between the analyst's forecast $f_{i k t}$ and the consensus forecast $c_{k \tau}$. This consensus forecast proxies for available public information up to the point where an analyst issues his forecast. It is calculated as the mean of all estimates up to $\tau$, excluding the estimate of the analyst $i$, who makes his estimate for quarter $t$ (analogous to Chen and Jiang 2006 and Zitzewitz 2001) ${ }^{4}$. The forecast error, the deviation from consensus as well as the forecast are deflated by the share price. Finally, we include a set of control variables $X_{i k t}$ that are known to be important determinants of the forecast error, while $\varepsilon_{i k t}$ is the regression error term.

We want to stress that the consensus forecast $c_{k \tau}$ possibly contains industry wide strategic biases of individual forecasts as modelled in equations (4) and (5). ${ }^{5}$ While it is likely that individual behavioral biases cancel out in the consensus, this is maybe less likely for individual strategic biases. In any case, the level of strategic distortion that an analyst decides upon is additional on potential strategic distortions present in the consensus. Our model thus captures the size of the strategic distortion, conditional on the average strategic distortion level that already exists.

\footnotetext{
${ }^{4}$ As a robustness check we also estimated a model that includes the deviation from the median consensus and we obtain similar results. These estimation results are available upon request.

${ }^{5}$ We thank one of the referees for pointing this out.
} 


\section{Empirical results}

\subsection{Data and descriptive statistics}

Quarterly earnings forecasts and stock price data are obtained from the Institutional Broker Estimate System (I/B/E/S) database, part of Thomson Financial. The earnings forecasts cover the period January 1996 until December 2006. The database is restricted to highly covered US companies with a December fiscal year end. High coverage is ensured by demanding a minimum average coverage of three analysts, and by deleting firms with an average market capitalization below $\$ 100$ million, an average market price below $\$ 5$, or a market price below $\$ 1$. Furthermore, the dataset is stripped from errors and potential companies in difficulties. As quarterly filings must be with the SEC within 45 days subsequent to the end of a quarter, observations of companies reporting later than this term are eliminated. In any given quarter, we keep the first forecast of analysts (similar to Chen and Jiang 2006, Francis and Philbrick 1993 and Hilary and Menzly 2006). Choosing the first forecast ensures the largest set of observations drawn from the same distribution. Moreover, first forecasts are most timely and thus most valuable to investors. We furthermore drop negative earnings forecasts. ${ }^{6}$ Such sample split is common in the earnings forecast literature as it allows one to analyze the forecasts for which analysts have put in all of their effort. Indeed, Hayes (1998) concludes that the incentive to gather information is most intense for stocks that are anticipated to give strong performance. Furthermore, McNichols and O'Brian (1997) indicate that analysts drop stocks with unfavorable future prospects. Additionally, there are systematic differences in characteristics of forecasts for negative versus non-negative earnings firms (Dowen 1996) ${ }^{7}$

Finally, we include a set of control variables in our analysis. Following Clement (1999), size of the covered firm $\left(\operatorname{Size}_{k t}\right)$, general $\left(\operatorname{Tot}_{\mathrm{Exp}} \mathrm{p}_{i t}\right)$ and firm specific experience $\left(\right.$ FirmExp $\left._{i k t}\right)$, two measures of task complexity (FirmCompl $l_{i t}$ and IndCompl $\left.l_{i t}\right)$ and forecast age $\left(A g e_{i k t}\right)$ are controlled for. Our final sample consists of 322,123 earnings forecasts, issued by 6,736 analysts on 2,773 companies.

\footnotetext{
${ }^{6}$ Deleting negative forecasts implies a reduction of the dataset of $11 \%$ from 362,040 to 322,123 forecasts. A sample of only positive forecasts still implies a symmetric loss function of forecast errors.

${ }^{7}$ For completeness, Section 5 reports the estimation results of our model applied to the subsample of negative earnings forecasts. These findings are in line with our main conclusions. Also a full sample analysis, including both positive as well as negative forecasts was performed with similar outcomes.
} 
A full description of all variables and their summary statistics and correlations can be found in Table 1 in Appendix B.

[Insert Table 1 about here]

\subsection{Main regression results}

The data set contains financial analysts' earnings forecasts for a particular stock at a certain point in time. This three way panel possibly contains unobserved effects such as analyst, time, firm and industry effects. To control for these unobserved effects, Petersen (2009) argues that OLS with clustered standard errors (if necessary multi-way) is the best estimation method. Comparing clustered standard errors, in each dimension or multiple dimensions, with White standard errors, we conclude that standard errors clustered by business group are sufficient. Table 2 summarizes the estimation results of our two-stage model $^{8}$. At the bottom of the table the weighting factor $k / h$ and the strategic factor $s$ are reported. They are calculated from the estimated parameters $\beta_{1}$ and $\beta_{2}$. Using the delta method, we know that the standard errors of $k / h$ and $s$ are the same as the standard errors of $\beta_{1}$ and $\beta_{2}$, respectively. For both factors, a two sided t-test determines whether they are significantly different from 1 .

[Insert Table 2 about here]

Formulating estimates and standard errors on the two factors $k / h$ and $s$ allows us to determine their significance and compare both biases in magnitude. The weighting factor $k / h$ is significantly larger than one at the $1 \%$ level. The estimate implies that financial analysts overweight the precision of their private information by about $2.5 \%$. The inflation factor $s$ is significantly larger than 1 at the $5 \%$ level. Financial analysts inflate their quarterly earnings forecast by roughly $3 \%$. Thus, even in the absence of relevant private information, analysts distort their forecasts. This result is important as it shows that an extension to the Chen and Jiang (2006) model is empirically relevant and allows us to better understand how analysts form their earnings forecasts.

\footnotetext{
${ }^{8}$ Adding quarter dummies for a possible fixed time effect or adding industry dummies for a possible fixed industry effect leads to similar results. All conclusions remain the same.
} 


\subsection{Identification of a behavioral bias and a strategic bias}

While the above full sample results indicate the coexistence of two separate distortions, further analysis can now shed light on the nature of these biases. Therefore, we re-estimate the model in different contexts or settings in an attempt to identify the behavioral from the strategic bias. In particular, we estimate our model separately for male and female analysts in an attempt to label one of the distortions as a behavioral overconfidence factor. We also estimate our model for a sample split at 2002, the year a new important regulatory framework for analysts was introduced. As this new regulation is targeted at banning conflicts of interest and thus at improving the quality of the analysts' research reports, we expect this change to have an effect on the strategic bias. Finally, to further confirm our model, we re-estimate the model on revised forecasts. This last analysis should pick up the observed walk down in earnings forecasts and should only have an impact on the strategic distortion.

Several academic studies show that men are more overconfident than women. Estes and Hosseini (1998) suggest that the most important factor for explaining investment decision confidence is the decision maker's gender. Deaux and Farris (1977) find that men claim more ability than do women and Prince (1993) reveals that men feel more competent than women with regard to financial matters. Of course, gender differences across the general population are not necessarily present among sophisticated individuals (see Croson and Gneezy 2009). However, Adams and Funk (2010) show that, even after controlling for observable characteristics, male and female directors do differ in their core values and attitudes towards risk. For example, female directors are less focused on power and more benevolent. In addition, Adams and Funk (2010) argue that gender effects may be driven by self-selection of women (see also Niederle and Vesterlund 2007). Further evidence on gender differences is also given by Can Inci et al. (2014) who argue that female executives seem to have a disadvantage in informal networks, and thus insider information, despite their equal formal status. Finally, Bosquet et al. (2014) show that male financial analysts are more likely to issue optimistic investment advice as compared to female analysts. Nevertheless, by estimating our two-stage model for male and female analysts we can analyze which distortion captures such behavioral difference between male and female analysts, and thus which distortion is likely to reflect behavioral factors. 
To examine differences between male and female analysts, the gender of each analyst in our sample is determined. In the I/B/E/S Brokers Translation File every analyst is listed by its last name and first initial. This dataset is merged with data from the corresponding annual edition of Nelson's Directory of Investment Research. This way the analyst's full name can be obtained on which basis gender is determined. We rely on a program that uses Google's database to analyze common patterns involving a first name ${ }^{9}$. The program determines whether the first name is more commonly used for a man or a woman. If there is uncertainty about the gender of an analyst, the history of that analyst is examined using the Internet to find out whether the analyst is male or female. For approximately $95 \%$ of the observations in the full dataset it is possible to determine the gender of the analyst. ${ }^{10}$ The other $5 \%$ of observations is removed from the dataset. Finally, we remove analysts that cover an excessive amount of stocks (95th percentile), assuming they are passing on information for an entire analyst team instead of one individual. The gender dataset contains 293,386 observations of 5,327 analysts on 2,770 firms. Overall, 806 or $15 \%$ of the analysts in the dataset are female.

To test our decision model on male and female analysts and to investigate the gender differences in overconfidence, we augment equation (8) with dummy variables that indicate whether an analyst is male or female:

$$
\begin{aligned}
F E_{i k t}= & \alpha_{1} D_{m}+\alpha_{2} D_{f}+\beta_{1, m}\left(D_{m} \times D e v_{i k t}\right)+\beta_{1, f}\left(D_{f} \times \text { Dev }_{i k t}\right) \\
& +\beta_{2, m}\left(D_{m} \times f_{i k t}\right)+\beta_{2, f}\left(D_{f} \times f_{i k t}\right)+\delta_{i, m}\left(D_{m} \times X_{i k t}\right) \\
& +\delta_{i, f}\left(D_{f} \times X_{i k t}\right)+\varepsilon_{i k t}
\end{aligned}
$$

We use both a male dummy $D_{m}=1$ in case of a male analyst and $D_{m}=0$ otherwise, as well as a female dummy $D_{f}=1$ in case of a female analyst and $D_{f}=0$ otherwise. This facilitates the extraction of two bias parameters we are interested in, as well as the computation of the associated standard errors. Note that we can take into account a male and female dummy at the same time as

\footnotetext{
${ }^{9}$ http://www.gpeters.com/names/baby-names.php

10 Also Green et al. (2009) and Kumar (2009) are able to match approximately $95 \%$ of the observations with gender.
} 
the regression model above is formulated without a (general) constant term. Compared to a split sample approach, such dummy approach has the advantage of allowing for a covariance between the male and female observations.

Table 3 shows estimation results from equation (8) presented separately for the male and female analysts. At the bottom of the table, the weighting factor $k / h$ and the factor $s$ for male and female analysts are presented. Compared to the rational Bayesian weight, male analysts overestimate their private information by $2.5 \%$. This result is significant at the $99 \%$ confidence level. For female analysts the degree of overweighting is estimated at only $0.4 \%$, and is not statistically significant from zero. The female weighting scheme is thus close to the rational scheme. More importantly, the difference between male and female analysts' weighting factor is significant at $95 \%$ (based on a one-sided test). While female analysts use rational Bayesian weights in processing public and private information, male analysts attach a weight to their personal information that is too high. This gender difference in the weighting of information leads us to conclude that the nature of this distortion is behavioral and can possibly be retraced to overconfidence. Moreover, this conclusion is further confirmed by analyzing the second-stage distortion. For this second-stage distortion, we find that male as well as female analysts positively inflate their Bayesian forecast, but that no significant gender difference can be observed. It is therefore most likely that this bias captures strategic incentives for which no gender -related prior exists.

[Insert Table 3 about here]

While the above gender analysis suggests that the misweighting of private information corresponds to a behavioral bias, we perform an additional test on the inflation factor to document that the inflation factor indeed captures strategic incentives. To this end, we focus on the 2002 analyst regulation which was directed at eliminating analysts' conflicts of interest and thus strategic behavior by analysts.

After the dot-com bubble, it was clear that financial analysts were not free from conflicts of interest and that their recommendations and earnings forecasts were biased. On May 10, 2002 the SEC therefore approved the NYSE Rules 351 and 472 and the NASD Rule 2711, collectively labelled 
"SRO rules". 11 These rules implement basic reforms to pursue the objectivity of financial analyst's research, and are directed specifically at the strategic behavior of financial analysts. If the second-stage inflation factor indeed corresponds to strategic incentives, we expect to observe a change in this factor. The behavioral first-stage factor should remain stationary.

We analyze the decision process for two separate time periods. The pre 2002 period runs from January 1996 until March 2002 and the post 2002 period runs from April 2002 until December 2006. Table 4 shows the estimation results of equation (8), the weighting factor $k / h$ and the strategic factor $s$ for both samples. Testing the decision model in a time frame before and after the new regulation shows that behavioral overconfidence is unaffected by the introduction of new regulation (difference $\mathrm{t}$-value of -0.69 is insignificant) but significantly different from zero in both sample periods. In line with our expectations, strategic distortion amounts to $5 \%$ before the new regulatory framework, and is estimated statistically significant at 99\%. After the new SRO rules have been implemented this strategic bias drops to a low $2 \%$, which is not significantly different from zero. Even though we cannot reject the hypothesis that the difference between both periods is zero, this decline in parameter value is in line with our expectations and supports the hypothesis that the inflation factor is strategic in nature.

\section{[Insert Table 4 about here]}

In the final analysis, we study the earnings forecast walk down, characterized by optimistic forecasts in the beginning of a quarter to pessimistic forecasts near the end of the quarter. Such walk down has been linked to management pleasing, and thus can be attributed to strategic behavior of analysts. Constructing a sample of final forecasts within a quarter allows us to study whether our strategic component captures this walk down.

\footnotetext{
11 These new rules target research analyst conflicts of interest and aim to promote greater independence of research analysts. To this end, actual and potential conflicts of interest need to be disclosed to investors. See Securities Exchange Act Release No. 45908, 67 FR 34968 (May 16, 2002). For a detailed explanation see http://www.sec.gov/rules/sro/34-48252.htm
} 
Richardson et al. (2004) document that analysts exhibit optimism at the start of the year, but then switch to pessimism in the final month prior to an earnings announcement. They suggest that management wants to sell stock on favorable terms after an earnings announcement. This is most likely with high market expectations after an earnings announcement but beatable targets before (see among others Skinner and Sloan 2002 and Bartov et al. 2002). Therefore, strategic behavior in terms of management pleasing can be observed in initial optimistic forecasts, but subsequent pessimistic forecasts before the next earnings announcement.

Financial analysts issue an earnings forecast for a certain company in a certain quarter, but they can make a revision during the quarter. Pursuing an in depth analysis of the decision process throughout the forecasting period, requires us to compare the first forecasts (the existing sample) with the last revisions. The sample of last revisions contains the last forecasts within a quarter of analysts who have already issued a previous forecast during that quarter. The same adjustments are made to this sample of last revisions as to the existing sample of first forecasts. This results in a sample of 60,047 earnings revisions, issued by 4,148 analysts on 747 companies.

Before reporting the regression results of the walk down of earnings forecasts, we descriptively compare the sample of first forecasts and last revisions over time. Figure 1 provides an overview of the quarterly average forecast error over time for the sample of first forecasts as well as for the sample of last revisions. This forecast error (FE), the difference between the forecast and the actual earnings, has an intuitive interpretation. A positive forecast error reflects optimistic behavior while a negative forecast error is defined as pessimism. The figure shows that, in the sample of first forecasts, average optimism turns into average pessimism after 2002. Analysts become less optimistic around 1999 and even pessimistic after 2002. This is in line with economic events such as the burst of the dot-com bubble and the introduction of new analyst regulation in 2002 as a reaction to a series of accounting scandals. The sample of last revisions shows that quarterly average forecast errors are almost consistently negative, implying that financial analysts are pessimistic when issuing their final revision. This is in line with findings of Markov and Tan (2006), who indicate that analysts have incentives to systematically underpredict earnings. Underpredicted earnings set beatable targets for firms' management, allowing for a positive earnings surprise. More importantly, the quarterly averages of the forecast error show that the last 
revision of financial analysts is always more negative than the first forecast. In sum, the figures already suggest a walk down at the consensus level and are therefore consistent with Richardson et. al. (2004). Using our decision model we further analyze whether financial analysts consciously and strategically deflate their earnings revision as captured by the second stage distortion

Table 5 presents estimation results obtained from the reduced form estimation equation (8) for the sample of last revisions. At the bottom of the table the weighting factor $k / h$ and the strategic factor $s$ are reported. We also report a two sided t-test to determine whether they are significantly different from one. While in Table 2 the strategic factor $s$ was significantly larger than one, the strategic factor $s$ is significantly smaller than one in the sample of last revisions. Thus, while financial analysts strategically inflate their initial forecasts by roughly $3 \%$ (see Table 2 estimates), they strategically deflate their final revisions by approximately $5 \%$, significant at the $1 \%$ level. In line with existing literature, we thus document a significant walk down (difference t-value of -3.68,

significant at the $1 \%$ level). At the same time, analysts still overweight their private information by about $3 \%$ when issuing their last revision (significant at the $1 \%$ level). This is similar to the degree of overconfidence observed in first forecasts (the difference t-value between the weighting factor from the last revisions and the first forecasts equals 0.30 and is insignificant). Therefore, in line with our expectations, only the strategic component alters when comparing first forecasts to last forecasts, while the weighting factor remains stable.

[Insert Table 5 about here]

The ability of our model to capture different settings or contexts is a confirmation of its setup. Not only is a two-stage decision model empirically relevant, the two distortions are also different in nature. Where the first-stage misweighting is driven by behavioral conduct, a second-stage inflation or deflation occurs for strategic reasons.

\section{Additional Robustness Test: Negative Earnings Forecasts}

Previous analyses are performed on positive earnings forecasts as Hayes (1998) argues that the incentive to gather information is most intense for stocks that are anticipated to give strong performance. Moreover McNichols and O'Brian (1997) indicate that analysts drop stocks with 
unfavorable future prospects. Table 6 summarizes the estimation results of our decision model as applied to negative earnings forecasts. Importantly, the interpretation of $s$ is different for the subsample. An $s$ smaller than one indicates strategic inflation (increasing the initial assessment), while $s$ larger than one indicates strategic deflation (lowering the initial assessment).

[Insert Table 6 about here]

The estimation results show significant overconfidence at the 5\% level. Financial analysts that do issue negative earnings forecasts overweight their private information by $6.8 \%$. Our estimation results indicate that analysts make their initial assessment less negative, however the coefficient is

not statistically significant. Our main results under Section 4 show how analysts consistently overweigh their private information and in addition inflate their assessment for strategic purposes. The results for the negative earnings forecasts are consistent with these main findings. Although not statistically significant, the strategic factor indicates inflation and again, analysts significantly overweigh their private information, even when it is negative.

\section{Conclusion}

Extensive research exists that aims to explain financial analyst behavior. However, the decision process of financial analysts is, to some extent, still a black box. In this paper we set up a two-stage model to further grasp the decision process of financial analysts. Our model builds on the model of Chen and Jiang (2006) by allowing for a distortion of forecasts whether or not analysts have private information. The inclusion of a second distortion also has the potential to separately define a behavioral bias from a strategic bias. When testing our model on a large dataset of quarterly earnings forecasts, we find that our model is empirically relevant. In a first stage, financial analysts overweight private information by $2.5 \%$ and in a second stage they inflate their Bayesian assessment of earnings by $2.9 \%$. Therefore, we conclude that our decision model with two distortions that impact forecasts differently coexist in financial analysts' earnings forecasts.

Estimating our model for different settings, we are able to label these distortions in terms of strategic and behavioral biases. In particular, we find that the gender stereotype that men are more overconfident than women is reflected in the first-stage misweighting of information, and not in the 
second-stage distortion. While male analysts overweight their private information, female analysts use a rational weighting scheme. Moreover, this gender difference is statistically significant. Analyzing the impact of the SRO ruling of 2002 further strengthens our model set up. Indeed, this SRO ruling, intended to decrease conflicts of interest and thus strategic behavior, had an impact on the second-stage distortion, but not on the first-stage misweighting of information. Strategic behavior becomes insignificant after the introduction of the SRO ruling, while behavioral overconfidence is significant both before and after the regulatory action. Finally, we show that the well-documented walk down in earnings forecasts from optimistic in the beginning of the forecast horizon to pessimistic near the end, is picked up by our model by the second-stage bias, while leaving the first stage bias unaffected. Again, this is in line with this second stage inflation/deflation capturing strategic distortions.

Overall, our results indicate that our two-stage model functions well and captures main empirical facts about analysts' decision process. Through increased flexibility of our model as compared to the Chen and Jiang (2006) model, we are able to separately define a behavioral and a strategic bias that coexist and we show that it matters empirically. 


\section{References}

Abarbanell J. 1991. Do Analysts' Forecasts Incorporate Information in Prior Stock Price Changes? Journal of Accounting and Economics, Vol.14. pp 147-165.

Adams, R.B. and Funk P. 2010. Beyond the Glass Ceiling: Does Gender Matter? Management Science, Vol 58(2). pp 219-235.

Barber B. M. and Odean T. 2001. Boys Will be Boys: Gender, Overconfidence, and Common Stock Investment. Quarterly Journal of Economics, Vol. 116(1). pp 261-292.

Bartov E., Givoly D. and Hayn C. 2002. The Rewards to Meeting or Beating Earnings Expectations. Journal of Accounting and Economics, Vol. 33(2). pp. 173 - 204.

Bosquet, K., P. de Goeij and Smedts, K. 2014. Gender heterogeneity in the sell-side analyst recommendation process. Finance Research Letters, Vol. 11(2). Pp. $104-111$.

Brown D. 1997. Analyst Forecasting Errors: Additional Evidence. Financial Analysts Journal, Vol.53(6). pp 81-88.

Can Inci, A., Narayanan M.P. and Nejat Seyhan H. 2014. Gender Differences in Executives' Access to Information. School of Business, University of Michigan. Working paper.

Chen Q. and Jiang W. 2006. Analysts' Weighting of Private and Public Information. Review of Financial Studies, Vol. 19(1). pp 319-355.

Clement M. B. 1999. Analyst forecast accuracy: Do ability, resources, and portfolio complexity matter? Journal of Accounting and Economics, Vol.27. pp 285-303.

De Bondt W. and Thaler H. 1990. Do Security Analysts Overreact? American Economic Review, Vol. 80(2). pp 52-57. 
Deaux K. and Farris E. 1977. Attributing Causes for One's Own Performance: The Effects of Sex, Norms, and Outcome. Journal of Research in Personality, Vol. 11(1). pp 59-72.

Dowen R. 1996. Analyst Reaction to Negative Earnings for Large Well-Known Firms. Journal of Portfolio Management, Vol. 23(1). pp 49-55.

Dugar A. and Nathan S. 1995. The Effect of Investment Banking Relationships on Financial Analysts' Earnings Forecasts and Investment Recommendations. Contemporary Accounting Research, Vol. 12(1). pp 131-160.

Easterwood C. and Nutt R. 1999. Inefficiency in Analysts' Earnings Forecasts: Systematic Misreaction or Systematic Optimism? Journal of Finance, Vol. 54(5). pp 1777-1797.

Estes R. and Hosseini J. 1988. The gender gap on wall street: An empirical analysis of confidence in investment decision making. Journal of Psychology, Vol. 122(6). pp 577-590.

Francis J. and Philbrick D. 1993. Analysts' decisions as products of a multi-task environment. Journal of Accounting Research, Vol. 31. pp 137-164.

Friesen G. C. and Weller P. A. 2006. Quantifying Cognitive Biases in Analyst Earnings Forecasts. Journal of Financial Markets, Vol. 9. pp 333-365.

Gervais S. and Odean T. 2001. Learning to be overconfident. Review of Financial Studies, Vol. 14. pp 1-27.

Green T., Jegadeesh N. and Tang Y. 2009. Gender and Job Performance: Evidence from Wall Street. Financial Analysts Journal, Vol. 65(6). pp 1-14.

Gu Z. and Wu J.S., 2003. Earnings Skewness and Analyst Forecast Bias. Journal of Accounting and Economics, Vol 3. pp 5-29. 
Hayes R. 1998. The impact of trading commission incentives on analysts' stock coverage decisions and earnings forecasts. Journal of Accounting Research, Vol.36. pp 299-320.

Hilary G. and Hsu C. 2013. Analyst Forecast Consistency. Journal of Finance, Vol. 68(1). pp 271-297.

Hilary G. and Menzly L. 2006. Does Past Success Lead Analysts to Become Overconfident. Management Science, Vol. 52(4). pp 489-500.

Ljungqvist A.; Marston F.; Starks L. T.; Wei K. D. and Yan H. 2007. Conflicts of interest in sell-side research and the moderating role of institutional investors. Journal of Financial Economics, Vol.85 (2). pp 420-456.

Martinez J.V. 2011. Information misweighting and the cross-section of stock recommendations. Journal of Financial Markets 14, 515-539.

Markov S. and Tan M. 2006. Loss function asymmetry and forecast optimality: Evidence from individual analysts' forecasts. Working Paper.

McNichols M. and O'Brien P. 1997. Self selection and analyst coverage. Journal of Accounting Research, Vol. 35. pp 167- 199.

Niederle, M. and L.Vesterlund, 2007. Do Women Shy Away from Competition? Do Men Compete too Much? The Quarterly Journal of Economics 122, 1067 - 1101.

O'Brian P. 1988. Analysts' forecasts as earnings expectations. Journal of Accounting and Economics, Vol. 10. pp 53-83.

Petersen M. A. 2009. Estimating standard errors in Finance Panel Data Sets: Comparing Approaches. Review of Financial Studies, Vol. 22. pp 435-480. 
Prince M. 1993. Women, men, and money styles. Journal of Economic Psychology, Vol. 14(1). pp 175-182.

Ramnath S; Rock S. and Shane P. 2008. A Review of Research Related to Financial Analysts' Forecasts and Stock Recommendations. International Journal of Forecasting, Vol. 24(1). pp 34-75.

Richardson S. A.; Teoh S. H. and Wysocki P. D. 2004. The walkdown to beatable analyst forecasts: the roles of equity issuance and insider trading incentives. Contemporary Accounting Research, Vol.21 (4). pp 885-924.

Schipper K. 1991. Analysts' forecasts. Accounting Horizons, Vol.5. pp 105-119.

Skinner D. J. and Sloan R. G. 2002. Earnings Surprises, Growth Expectations, and Stock Returns or Don't Let an Earnings Torpedo Sink Your Portfolio. Review of Accounting Studies, Vol.7. pp 289-312.

Thompson S. 2006. Simple Formulas for Standard Errors that Cluster by Both Firm and Time. Journal of Financial Economics 99, 1-10.

White H. 1984. Asymptotic Theory for Econometricians. Academic Press.

Zitzewitz E. 2001. Opinion-Producing Agents: Career Concerns and Exaggeration. Working Paper. 


\section{Appendix A: Deriving the regression equation}

To derive to the estimation equation as summarized in equation (8), we start from the expected forecast error

$$
\begin{aligned}
E(F E \mid x, c) & =E(f-c \mid x, c) \\
& =s(k x+(1-k) c)-(h x+(1-h) c) \\
& =s k x+(s-s k) c-h x-(1-h) c \\
& =\frac{h}{k} c-\frac{h}{s k} f+(f-c)
\end{aligned}
$$

Rearranging allows for a clear identification of both the stages of biases impacting an analyst's forecast and forecast error:

$$
E(F E \mid x, c)=\left(1-\frac{h}{k}\right)(f-c)+\frac{h}{k}\left(\frac{s-1}{s}\right) f
$$

Applying a first-order Taylor approximation to both coefficients in the equation above around $\mathrm{k} / \mathrm{h}$ $=1$ and $s=1$, the reduced form moment condition is transformed into

$$
\begin{aligned}
E(F E \mid x, c) & =\left(\frac{k}{h}-1\right)(f-c)+(s-1) f \\
& =\beta_{1}(f-c)+\beta_{2} f
\end{aligned}
$$

This allows for a clear separation of the two biases in $\beta_{1}$ and $\beta_{2}$ respectively. 


\section{Appendix B: Tables}

\section{Table 1: Summary Statistics}

Panel A of this table presents the descriptive statistics of the forecast error, the deviation from consensus, the earnings forecast (deflated) and the control variables used in equation (9). Outliers are removed by deleting the top and bottom $0.1 \%$ for the variables forecast error, deviation and earnings forecast. The earnings forecast data is obtained from I/B/E/S. Panel B of this Table shows the correlations

FE is the difference between the earnings forecast and the actual, deflated by the share price. Dev is the difference between the earnings forecast and the consensus forecast, deflated by the share price. $\mathbf{f}$ is the analyst's earnings forecast, deflated by the share price. Age is the number of days between the issue of the analyst's earnings forecast and the reporting date of the actual earnings. Size is the logarithm of the market capitalization, calculated in the month prior to the forecast. FirmExp is the number of quarters an analyst has followed a certain stock. TotExp is the number of quarters the analyst is present in the data set. For both ability variables data starting from 1992 is used to prevent all analysts from starting with the same experience in 1996. FirmCompl is the number of companies an analyst follows during a quarter. IndCompl is the number of sectors an analyst follows during a quarter. I/B/E/S identifies 11 sectors using a proprietary classification scheme for companies with similar business lines.

Panel A: Descriptive Statistics

\begin{tabular}{lrrrr}
\hline & Mean & Stdev & Min & Max \\
\hline FE & $3 \mathrm{e}-0.06$ & 0.01 & -0.25 & 0.68 \\
Dev & 0.01 & 0.01 & -0.11 & 0.53 \\
f & 0.01 & 0.01 & 0.00 & 0.53 \\
Age & 73.87 & 26.13 & 1.00 & 143.00 \\
Size & 7.93 & 1.32 & -5.32 & 12.34 \\
FirmExp & 11.46 & 10.36 & 1.00 & 59.00 \\
TotExp & 20.72 & 13.39 & 1.00 & 59.00 \\
FirmCompl & 9.22 & 5.89 & 1.00 & 67.00 \\
IndCompl & 1.71 & 0.94 & 1.00 & 9.00 \\
\hline
\end{tabular}

Panel B: Correlations

\begin{tabular}{llllcccccc}
\hline & FE & Dev & f & Age & Size & FirmExp & TotExp & FirmCompl & IndCompl \\
\hline FE & 1.00 & 0.05 & 0.04 & 0.02 & -0.05 & 0.00 & -0.01 & -0.01 & -0.01 \\
Dev & & 1.00 & 0.41 & 0.34 & -0.06 & 0.01 & 0.03 & 0.00 & 0.04 \\
F & & & 1.00 & -0.02 & 0.03 & 0.08 & 0.06 & 0.11 & -0.03 \\
Age & & & & 1.00 & -0.04 & -0.01 & 0.03 & -0.08 & 0.07 \\
Size & & & & & 1.00 & 0.21 & 0.09 & 0.12 & -0.10 \\
Firmexp & & & & & & 1.00 & 0.60 & 0.17 & 0.02 \\
TotExp & & & & & & & 1.00 & 0.21 & 0.12 \\
FirmCompl & & & & & & & & 1.00 & 0.12 \\
indCompl & & & & & & & & 1.00 \\
\hline
\end{tabular}




\section{Table 2: Main Estimation Results}

This table presents coefficient estimates and t-values for the reduced form estimation equation (equation 8 ). The data cover the period January 1996 - December 2006 and only positive forecasts have been used, yielding a dataset of 322,123 observations. A firm fixed effects estimation is used with clustered standard errors by business group. These clustered standard errors are White (1984) standard errors adjusted to account for possible correlation within a cluster, i.e. business group. This table also reports the estimation results for the weighting factor $\frac{k}{h}$ and the strategic factor $s$. For both factors the two sided hypothesis test whether they are significantly different from 1 is performed. ***,*** indicate significance at the $10 \%, 5 \%$ and $1 \%$ level, respectively.

\begin{tabular}{l|rc}
\hline & Coeff. & t-value \\
\hline Dev $\left(\boldsymbol{\beta}_{\boldsymbol{I}}\right)$ & $24.9 \mathrm{e}-03$ & $4.17^{* * *}$ \\
$\mathbf{f}\left(\boldsymbol{\beta}_{2}\right)$ & $29.3 \mathrm{e}-03$ & $2.13^{* *}$ \\
Age & $49.0 \mathrm{e}-07$ & $3.05^{* * *}$ \\
Size & $-20.0 \mathrm{e}-05$ & $-1.83^{*}$ \\
FirmExp & $-18.0 \mathrm{e}-07$ & -0.96 \\
TotExp & $8.0 \mathrm{e}-07$ & 0.66 \\
FirmCompl & $-7.0 \mathrm{e}-07$ & -0.48 \\
IndCompl & $-7.0 \mathrm{e}-07$ & -0.08 \\
\hline k/h & 1.025 & $4.17^{* * *}$ \\
s & 1.029 & $2.13^{* *}$ \\
\hline Adj. $\mathbf{R}^{2}$ & \multicolumn{2}{|c}{$0.47 \%$} \\
Nobs & \multicolumn{2}{|c}{322,123} \\
\hline
\end{tabular}




\section{Table 3: Estimation results for gender-stereotype: a behavioral bias}

This table presents estimation results for the reduced form estimation equation (8). The data cover the period January 1996 - December 2006 and only positive forecasts have been used, yielding a dataset of 322,123 observations. A firm fixed effects estimation is used with clustered standard errors by business group. These clustered standard errors are White (1984) standard errors adjusted to account for possible correlation within a cluster, i.e. business group. At the bottom, this table presents the estimation results for the weighting factor $k / h$ and the strategic factor $s$ for the male and female analysts. For both factors the two sided t-test whether they are significantly different from 1 is performed. For the gender difference with respect to the factors, a two sided t-test is reported in the final column. *,**,*** indicate significance at the $10 \%, 5 \%$ and $1 \%$ level, respectively.

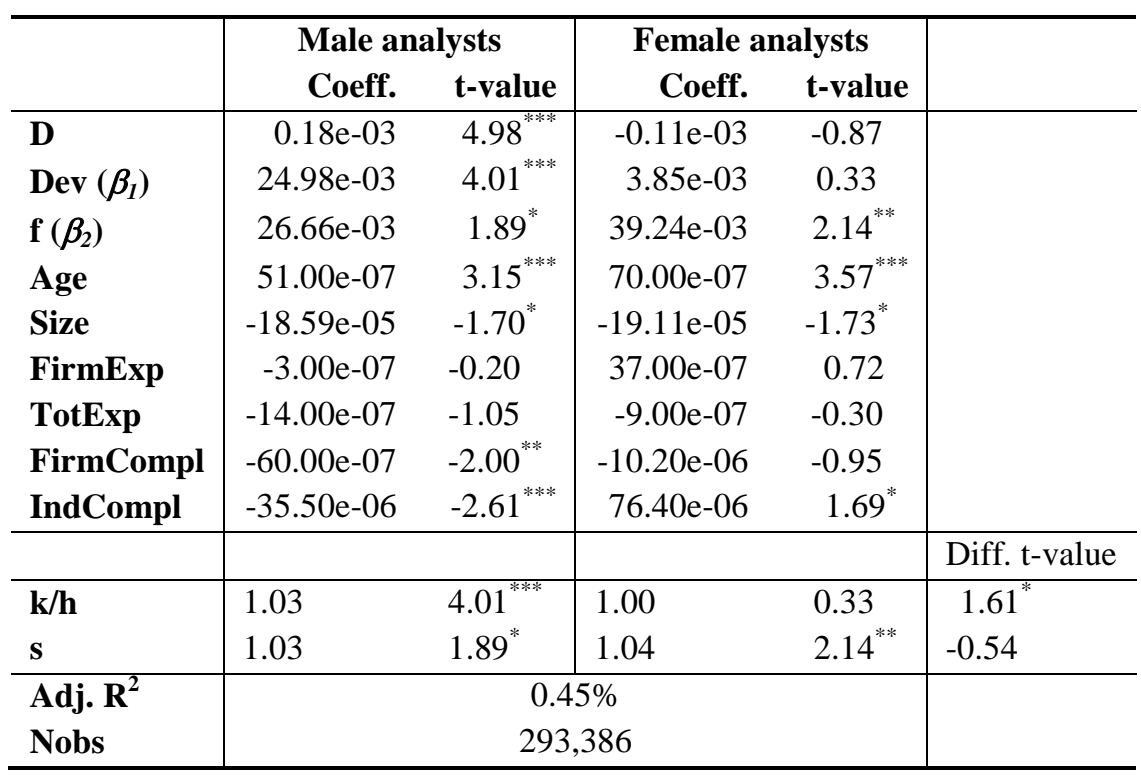




\section{Table 4: Estimation results for the 2002 SRO regulation change: strategic distortion}

This table presents coefficient estimates and t-values for the reduced form estimation equation (8) for the pre-2002 period and the post-2002 period. The data cover the period January 1996 - December 2006 and only positive forecasts have been used, yielding a dataset of 322,123 observations. The cutoff point is the second quarter of the year 2002 . The pre-period runs from January 1996 until April 2002 and the post-period runs from April 2002 until December 2006. For all regressions firm fixed effects are used with clustered standard errors by business group. These clustered standard errors are White (1984) standard errors adjusted to account for possible correlation within a cluster, i.e. business group. At the bottom, this table presents the estimation results for the weighting factor $k / h$ and the strategic factor $s$. For both factors the two sided hypothesis test whether they are significantly different from 1 is performed. In the final column a difference t-value is reported on the difference between the weighting factor and the strategic factor pre- and post-2002. The earnings forecast data is obtained from I/B/E/S. ***,*** indicate significance at the $10 \%, 5 \%$ and $1 \%$ level, respectively.

\begin{tabular}{|c|c|c|c|c|c|}
\hline & \multicolumn{2}{|c|}{ Pre 2002} & \multicolumn{2}{|c|}{ Post 2002} & \\
\hline & Coeff. & t-value & Coeff. & t-value & \\
\hline $\operatorname{Dev}\left(\beta_{1}\right)$ & $34.0 \mathrm{e}-03$ & $3.18^{* * *}$ & $24.5 \mathrm{e}-03$ & $2.90^{* * *}$ & \\
\hline $\mathbf{f}\left(\beta_{2}\right)$ & $51.6 e-03$ & $2.73^{* * *}$ & 17. $4 \mathrm{e}-03$ & 0.74 & \\
\hline Age & $80.0 \mathrm{e}-07$ & $4.75^{* * * *}$ & $26.0 \mathrm{e}-07$ & 1.17 & \\
\hline Size & $-26.0 e-05$ & $-1.93^{*}$ & $20.0 \mathrm{e}-05$ & 1.05 & \\
\hline FirmExp & $22.0 \mathrm{e}-07$ & 0.73 & $21.0 \mathrm{e}-07$ & -1.39 & \\
\hline TotExp & $-56.0 e-07$ & $2.28^{* * *}$ & $20.0 \mathrm{e}-08$ & 0.19 & \\
\hline FirmCompl & $-58.0 e-07$ & $-2.24^{* * *}$ & $-11.0 \mathrm{e}-07$ & -0.37 & \\
\hline \multirow[t]{2}{*}{ IndCompl } & $-14.7 \mathrm{e}-06$ & -0.93 & $-31.0 e-07$ & -0.23 & \\
\hline & & & & & Diff. t-value \\
\hline $\mathbf{k} / \mathbf{h}$ & 1.03 & $3.18^{* * * *}$ & 1.02 & $2.90^{* * * *}$ & -0.69 \\
\hline $\mathbf{s}$ & 1.05 & $2.73^{* * *}$ & 1.02 & 0.74 & -1.14 \\
\hline Adj. $R^{2}$ & \multirow{2}{*}{\multicolumn{2}{|c|}{$\begin{array}{c}1.28 \% \\
154,210\end{array}$}} & \multirow{2}{*}{\multicolumn{2}{|c|}{$\begin{array}{c}0.26 \% \\
167,913\end{array}$}} & \\
\hline Nobs & & & & & \\
\hline
\end{tabular}




\section{Table 5: Empirical Results for Forecast Walkdown: strategic distortion}

This table presents coefficient estimates and t-values for the reduced form estimation equation (8) for the sample of last revisions. The data cover the period January 1996 - December 2006 and only positive forecasts have been used. A firm fixed effects estimation is used with clustered standard errors by business group. These clustered standard errors are White (1984) standard errors adjusted to account for possible correlation within a cluster, i.e. business group. At the bottom, this table presents the estimation results for the weighting factor $k / h$ and the strategic factor $s$. For both factors the two sided hypothesis test whether they are significantly different from 1 is performed. The earnings forecast data is obtained from $\mathrm{I} / \mathrm{B} / \mathrm{E} / \mathrm{S}$. ***,*** indicate significance at the $10 \%, 5 \%$ and $1 \%$ level, respectively.

\begin{tabular}{l|rc}
\hline & Coeff. & t-value \\
\hline Dev $\left(\boldsymbol{\beta}_{\boldsymbol{1}}\right)$ & $27.5 \mathrm{e}-03$ & $4.29^{* * * *}$ \\
$\mathbf{f}\left(\boldsymbol{\beta}_{2}\right)$ & $-47.5 \mathrm{e}-03$ & $-3.02^{* * *}$ \\
Age & $-7.00 \mathrm{e}-07$ & -0.28 \\
Size & $20.00 \mathrm{e}-05$ & 1.55 \\
FirmExp & $-27.00 \mathrm{e}-07$ & $-1.70^{* *}$ \\
TotExp & $-5.00 \mathrm{e}-07$ & -0.45 \\
FirmCompl & $-3.0 \mathrm{e}-07$ & -0.09 \\
IndCompl & $-72.0 \mathrm{e}-07$ & -0.36 \\
\hline k/h & 1.028 & $4.29^{* * *}$ \\
$\mathbf{S}$ & 0.952 & $-3.02^{* * *}$ \\
\hline Adj. $\mathbf{R}^{2}$ & \multicolumn{2}{|c}{$0.93 \%$} \\
Nobs & \multicolumn{3}{|c}{60,047} \\
\hline
\end{tabular}




\section{Table 6: Empirical results for Negative Earnings Forecasts only}

This table presents coefficient estimates and t-values for the reduced form estimation equation (8) for negative earnings forecasts. The data cover the period January 1996 - December 2006. A firm fixed effects estimation is used with clustered standard errors by industry. We use 11 industry groups to cluster the standard errors instead of 211 business groups. The sample size of the last revision sample is not sufficient to have enough observations for each of the 211 clusters. At the bottom, this table presents the estimation results for the weighting factor $k / h$ and the strategic factor $s$. For both factors the two sided hypothesis test whether they are significantly different from 1 is performed. The earnings forecast data is obtained from $\mathrm{I} / \mathrm{B} / \mathrm{E} / \mathrm{S}$. *,**,*** indicate significance at the $10 \%, 5 \%$ and $1 \%$ level, respectively.

\begin{tabular}{l|rc}
\hline & Coeff. & t-value \\
\hline Dev $\left(\boldsymbol{\beta}_{\boldsymbol{I}}\right)$ & $67.6 \mathrm{e}-03$ & $2.84^{* *}$ \\
$\mathbf{f}\left(\boldsymbol{\beta}_{2}\right)$ & $-20.9 \mathrm{e}-03$ & -0.40 \\
Age & $33.1 \mathrm{e}-06$ & $3.19^{* * *}$ \\
Size & $-12.1 \mathrm{e}-04$ & -0.60 \\
FirmExp & $48.8 \mathrm{e}-06$ & $1.37^{*}$ \\
TotExp & $-6.8 \mathrm{e}-06$ & -0.34 \\
FirmCompl & $-14.3 \mathrm{e}-06$ & -0.35 \\
IndCompl & $21.7 \mathrm{e}-05$ & $-3.70^{* * *}$ \\
\hline k/h & 1.07 & $2.84^{* *}$ \\
s & 0.98 & -0.40 \\
\hline Adj. $\mathbf{R}^{2}$ & \multicolumn{2}{|c}{$0.60 \%$} \\
Nobs & \multicolumn{2}{|c}{39,917} \\
\hline
\end{tabular}




\section{Figure 1: Average FE of First Forecast and Last Revision}

This figure shows the quarterly average FE for the sample of first forecasts and the sample of last revisions over time, deflated by the stock price. The time period covers January 1996 until December 2006.

Quarterly average FE



